\title{
1. A Qualitative Study of Medical Student Socialization in Malawi's College of Medicine: Preclinical Training and Identity
}

\section{Claire Wendland ${ }^{1} \&$ Chiwoza Bandawe $^{2}$}

1. Universiry of Wisonconsin

2. College of Medicine, Blantyre

\section{Introduction}

For five decades, social scientists have examined the moral and personal impact of medical training. Though the standard structure of medical education - two years of primarily basic science training followed by two to three years of primarily clinical work - has remained stable during this time, the content of medical curricula and the profile of entering medical students have changed dramatically. When Becker and colleagues ${ }^{1}$ first interviewed students in 1950s North America, their respondents were nearly all white Protestant married males from upper-middle-class backgrounds. Though medical schools remain less diverse than society as a whole, they have experienced a sharp rise in gender, religious, ethnic, economic, and sexual diversity.

The early studies showed most students beginning school with idealistic notions about helping people. By graduation, they had become emotionally detached, cynical, mercenary, conservative, and inescapably reductionistic in their vision of both the human body and the processes used to heal it. They were increasingly focused on technology and procedures and less capable of (or interested in) seeing the person as a whole. Medical students had also become unusually vulnerable to mental illness, suicide, and substance abuse.

Medical educators deliberately attempted to reshape such outcomes, responding both to their own concerns and to popular unhappiness about dehumanizing treatment from doctors. Common approaches to reform included altering the curriculum to include course material on ethics and values, and deliberate recruitment of "different" types of students: women, minorities, those with more humanistic bents. The hopes for this type of reform have not been fulfilled. The most recent large study of medical socialization found essentially the same outcomes - in women and men, whites and ethnic minorities, artists and biochemists - that researchers had found in the homogenous medical classes of decades past. ${ }^{2}$

The research we describe here addresses a serious flaw in the existing literature. Virtually all research on medical socialization has been conducted in North America, with a few smaller studies in Northern Europe. Yet in the past hundred and fifty years, biomedical education has become a global phenomenon. Fewer than ten percent of the world's medical schools are in North America, and the fastest growth in medical school numbers is in Africa (followed by Asia and Latin America). ${ }^{3}$ Medical educators have often assumed that medical education is simply a culturally neutral technology transfer, ${ }^{4}$ while critical social scientists tend to assume that it is part of a steadily creeping biomedical hegemony that creates and serves a new elite. ${ }^{5}$ No one, however, has actually studied the impact of medical training outside the global North, or on students in poor countries.

This omission cannot simply be considered a "gap" in the literature: it calls into question the generalizability of, and explanations for, the findings themselves. Are the strikingly consistent findings of medical socialization research truly inherent in medical education itself, evidence of some sort of global medical culture, or are they at least in part products of a wealthy Northern setting? What happens when the biomedical training studied in the "developed" world is exported to the "developing" one?

\section{Methods}

This research was a qualitative project, collaboratively designed to investigate the professional socialization of students at the University of Malawi's College of Medicine. ${ }^{i}$ Malawi is both culturally and economically very different from the settings in which researchers have previously examined medical socialization. For one thing, it is dramatically poorer, dependent on subsistence agriculture and foreign aid. Longstanding problems with high unemployment and rural poverty improved for some time after independence but then deteriorated. Like several other nations in sub-Saharan Africa, Malawi has lost ground in economic and health measures over the past two decades, under the combined influences of the structural adjustment programs mandated by international lending agencies, the HIV/AIDS pandemic, and unstable climatic (and sometimes political) conditions. Infant, child, and maternal mortality rates are among the worst in the world, and health facilities are chronically understaffed and underfunded.

Culturally, Malawi also differs from the Northern settings of most medical education research. Southeast African society has been described by many as communally focused, ${ }^{6}$ with mutual obligation among extended kin networks rather than the Northern style individualism that has been a major feature in previous medical socialization studies. To investigate doctors' identity formation in this setting, we used a cross-sectional and sequential method involving focus group discussions, interviews, and a questionnaire, and moving from open-ended and general to more specific questions. The two authors devised this method and the initial set of questions in close collaboration; one (CW) did the actual data collection. Interview questions were derived from themes that came up in focus groups, and items on the questionnaire were derived from themes in both focus groups and interviews, a procedure that draws on grounded theory methodology.

The results presented here are based on 4 focus groups with a total of 20 students, 31 student and 7 intern interviews, and 121 questionnaires. Questionnaires were returned from 84\% of all medical students during the 2002-2003 study period; interviews or focus groups included $31 \%$ of all students (students who participated in both are counted only once), distributed among the five years of training.

Students were not compensated for interviews, focus groups, or questionnaires, and the researchers are very grateful for their voluntary participation. The study was approved by the University of Malawi College of Medicine Research and Ethics Committee, and by the University of Massachusetts 
at Amherst; written consent was obtained for all interviews. Interview and focus group transcripts were coded for thematic content using QSR*N6 qualitative research software. We present primarily interview data, reporting here as major themes those that arose in at least twenty-five percent of interviews. We supplement these themes with some questionnaire and focus group data. Where statistical analysis was suitable, Likert-scale items from questionnaires were analyzed using STATA 7, and effects of binomial categories, linear variables, and ordinal nonlinear variables on Likert scores were measured using t-tests, linear regression, and ordered logit regression, respectively.

\section{Results $^{\text {ii }}$ \\ Demographics}

At the time of the study two thirds of the student body was male. Interview data suggested that most students come from a relatively wealthy, urban and well-educated stratum of Malawian society. Socioeconomic status is difficult to measure here, and in the questionnaire we used parental education as a proxy measure. The educational levels of students' mothers was particularly striking; one can calculate that roughly $12 \%$ of Malawi's college-educated women forty or older had a child in the College of Medicine at the time of the study. On average, female students were more likely to have highly educated parents than male students $(\mathrm{p}<0.005$ for paternal and $\mathrm{p}<0.0001$ for maternal education), a class difference that makes any analysis of results based on gender alone problematic. A few older students were children of illiterate farmers, but the socioeconomic diversity of the medical school generally appeared to be decreasing as the deterioration of Malawi's structurally adjusted public schools, and the disappearance of merit-based secondaryschool scholarships, make education a chancier route to social mobility.

A substantial minority of students also had previous clinical experience, sometimes as technicians or nurses, but mostly as clinical officers. These students tended to be male, older than the average student (by a mean of 7 years, $\mathrm{p}<.01$ ), and on average from more educationally marginal families (by mean paternal education, $\mathrm{p}<.01$ )

Many students with clinical experience volunteered in interviews that they felt they were treated differently by faculty and staff and had more to prove, as did a majority $(78 \%)$ of female students. No other students reported this feeling.

\section{Reasons for Choosing Medicine}

When asked what drew them to medicine as a career, students were most likely to answer that they wanted to help people, were encouraged by their families, or were good at sciences (see Table 1). A substantial minority of students reported that their desire to be doctors was to "uplift Malawi," or "improve the health of the nation" often referring specifically to altering the country's doctor-to-patient ratio. In addition, one third of students had been driven to medicine by a close encounter with illness: either their own $(23 \%)$ or of someone close to them (13\%). Questionnaire results were similar.
Table 1 Factors influencing students toward medicine: interview themes (students)

\begin{tabular}{ll}
\hline Factor & Students mentioning \\
\hline Wanted to help people & $42 \%$ \\
Family encouragement or pressure & $39 \%$ \\
Good at sciences & $39 \%$ \\
$\begin{array}{l}\text { Experience with illness of self or someone } \\
\text { close to me }\end{array}$ & $36 \%$ \\
Wanted to improve conditions in Malawi & $26 \%$ \\
$\begin{array}{l}\text { Admired medical personnel l've } \\
\text { encountered }\end{array}$ & $26 \%$ \\
\hline
\end{tabular}

\section{Experience of Pre-Clinical Training}

The first two school years consist primarily of basic science training. This process looks very similar to medical school in many other places, though books and other supplies are scarcer. Students dissect cadavers and look at tissues under microscopes, memorize physiology and biochemistry, and take seemingly endless examinations.

Two major themes emerge from interviews among students in the preclinical years. The first concerns a homogenization of identity. Like their North American counterparts, Malawian students quickly - and to some extent deliberately - become more homogenous in style, dress, and manner. Old markers of class and regional identity (for instance, certain regional languages, behaviors learned at specific preparatory schools, patterns of socialization by gender and city of origin) are dropped in favor of "mature" physician behaviors. In focus groups and interviews, students described learning to behave, dress, and speak like doctors as a process of "blending" with other medical colleagues and of conforming to the behavior and status society expects of doctors. Students report newfound maturity and improved social skills, especially the skills to relate to people they perceive as different from themselves, as the most important personal changes they undergo during their first two years of training (see Table 2). Some also described drawing away from non-medical friends and family.

Table 2 Changes in self since training began: student interview themes (students and interns)

\begin{tabular}{ll}
\hline Change & Students mentioning \\
\hline Have matured & $52 \%$ \\
Better social skills & $35 \%$ \\
Deep knowledge of body & $35 \%$ \\
$\begin{array}{l}\text { Relationships with friends or family } \\
\text { outside medicine changed }\end{array}$ & $32 \%$ \\
More responsible & $26 \%$ \\
\hline
\end{tabular}

The second major theme is that of scientific knowledge as key to professional identity. During the pre-clinical period, students pride themselves on their ability to memorize enormous amounts of material and to understand the workings of the body; they embrace the identity of doctoras-scientist; they learn to think of the human body as an amazing machine, with malfunctions that can be diagnosed and corrected by the skillful application of scientific knowledge. Thirty-five percent of pre-clinical students saw a deep knowledge of the body as an important personal change during their medical training. They felt that through 
their training they learned to "see" the physiologic processes that occur beneath the skin, a knowledge that separated them from the general public and that made them comfortable with the status they were granted as doctors, "even if I don't know what to do," as one put it. The few students who mentioned traditional healing discussed their medical knowledge as a way to "see through" such practices, but in interviews, students more often cited their knowledge to distinguish themselves from another group: clinical officers. As one put it, "Maybe that's what differentiates us from CO's... we have to know almost everything. Compared to them where they just have to know surface issues, and we have to know the depth of everything." In fact, every student who actually was himself a clinical officer commented at some point on the depth of his new knowledge as key to the attainment of doctor status.

\section{Discussion}

How do these experiences of preclinical medical training compare to those previously reported among students in North America (or rarely, Western Europe)?

- Previous studies show that most medical students quickly take on a mechanistic view of humans, apparently at least in part to detach from unwelcome emotions. ${ }^{1,8}$ ${ }^{10}$ Adoption of a formal scientific language to discuss the body while rejecting subjectivity is an important mechanism of this depersonalizing process. ${ }^{11}$ Our results suggest that Malawian students initially show a similar shift toward a view of humans that emphasizes the universal body, knowable only by the doctor. Anatomy and physiology training especially seem to bring about this shift. However, no findings in this study suggested that such a view was important for control of unwelcome emotions - students did not speak, for instance, of dissection as requiring suppression of their "natural feelings" of horror. As we will show in a second paper, this shift to depersonalization is reversed later.

- Students report difficulty leaving detachment at work. Northern student doctors consistently report increasing difficulty in relationships with non-medical family and friends. ${ }^{2,12}$ They attribute these changes to the pressures of their medical curriculum, particularly to limitation of time and violation of human norms. (North American medical students, for instance, often report feeling they are set apart in some essential way from "normal" people after they have dissected bodies.) Some Malawian students also report increasing distance from family, and a few cited time pressures. Most, however, attributed distance instead to increased financial pressures related to loss of income, and to status differentials. Malawians also described improved maturity and social skills, not typically found in Northern students' self-reports.

- Northern students' identities become more and more closely tied to their future profession, often leading to deep internal prohibition of criticism of the profession or of fellow physicians. ${ }^{1,2}$ Powerful factors in this process include the institutional hierarchy of the training program and the student peer group. ${ }^{11,12}$ However, Northern students rarely think of themselves as doctors before graduation, and almost never during their preclinical years. ${ }^{2,13}$ There is strong evidence among Malawian students for uptake of a doctor-scientist identity, and the student peer group is clearly an important part of this process of identification. Notably, students take on the identity of "doctor" much earlier in training than is typical among Northern students. We also did not find evidence that Malawian students prohibited criticism of fellow clinicians. As we will report subsequently, in their clinical years students actually become more critical of their profession.

- Northern students frequently report a desire for anonymity. ${ }^{2}$ This anonymity may be better thought of as "conformity," as students compete with each other to be perceived by faculty as most closely fitting the pattern of ideal doctor. As part of this conformity they dress and speak more conservatively. They also tend to become more conservative, ${ }^{13-15}$ demonstrating increased homogeneity when responding to moral and political issues. ${ }^{15,16}$ First-person accounts may refer to this homogenization as a destructive process,${ }^{17}$ but sociologists also describe students as welcoming some degree of homogenization as a part of becoming "real doctors." ${ }^{13}$ In Malawi, students also quickly - and to some extent deliberately - become more homogenous in style, dress, language and manner, shedding old markers of group identity in favor of new markers of physician identity. We found no evidence of increasing political conservatism, however, and in fact found some evidence suggesting the opposite.

In summary, while Malawian students share some developmental patterns with theircolleagues in North America and the United Kingdom, even during the first two years of medical training notable differences emerge. Malawian students are more likely to be motivated by nationalist and religious impulses to enter medicine, motivations that will be of importance later in their training. They take on the identity of "doctor" much earlier, distinguishing themselves sharply from clinical officers, and seem to occupy a higher status.

\section{Conclusion}

The study has shown that College of Medicine students in Malawi do go through a socialization process as do medical students in the North where medical school socialization has been studied extensively. What stands out here though, is that the socialization itself is idiosyncratic to the cultural context and socioeconomic situation on the ground. Socialization is also tied to meaning making of the role of the doctor, which carries with it a sense of responsibility in a professional and social sense.

\section{References}

1. Becker HS, Geer B, Hughes EC, Strauss A. Boys in White: Student Culture in Medical School. Chicago: University of Chicago Press, 1961.

2. Beagan BL. Personal, public, and professional identities: conflicts and congruences in medical school. University of British Columbia: PhD Dissertation in Sociology, 1998.

3. Wendland C. Making Doctors in Malawi: Local Exigencies Meet Global Identities in an African Medical School. University of Massachusetts at Amherst: PhD Dissertation in Anthropology, 2004.

4. Gallagher EB. Convergence or divergence in Third World medical education? An Arab study. J Health Soc Behav 1988;29:385-400.

5. Morsy SA. Political Economy in Medical Anthropology. In: Sargent CF, Johnson TM, eds. Medical Anthropology: Contemporary Theory and Method. Revised ed. Westport, CT: Praeger, 1996:21- 
40.

6. Bandawe CR. Psychology brewed in an African pot: Indigenous philosophies and the quest for relevance. Higher Ed Pol 2005;18:289-300.

7. Glaser BG, Strauss AL. The Discovery of Grounded Theory: Strategies for Qualitative Research. Chicago: Aldine Publishing Company, 1967.

8. Anspach RR. Notes on the sociology of medical discourse: the language of case presentation. J Health Soc Behav 1988;29:357375.

9. Good B, Delvecchio-Good M-J. Learning medicine. In: Lindenbaum S, Lock M, eds. Knowledge, Power and Practice. Berkeley: University of California Press, 1993:81- 107.

10. Hafferty FW. Into the Valley: Death and the Socialization of Medical Students. New Haven, CT: Yale University Press, 1991.

11. Sinclair S. Making doctors: an institutional apprenticeship. Oxford: Berg, 1997.

12. Konner M. Becoming a Doctor: A Journey of Initiation in Medical School. New York: Viking, 1987.

13. Beagan BL. Neutralizing differences: producing neutral doctors for (almost) neutral patients. Soc Sci Med 2000;51:1253-1265.

14. Shapiro M. Getting doctored: critical reflections on becoming a physician. Santa Cruz, CA: New Society Publishers, 1987.

15. Leserman J. Men and women in medical school: how they change and how they compare. New York: Praeger, 1981.

16. Self DJ, Schrader DE, Baldwin DC, Jr., Wolinsky FD. A pilot study of the relationship of medical education and moral development. Acad Med 1991;66:629.

17. LeBaron C. Gentle Vengeance: An Account of the First Year at Harvard Medical School. New York: Penguin, 1982.

\section{Notes}

i. Data collection, analysis and some writing for this project were greatly facilitated by the generous support of Social Science Research Foundation's International Dissertation Field Research Fellowship (2002-2003) and the University of Massachusetts at Amherst's Graduate School Fellowship (2002-2003 and 2003-2004), awarded to the first author.

ii. Space constraints mean we present only a brief summary here. Readers interested in more detail are referred to the first author's 2004 dissertation. ${ }^{3}$ Copies of this text are on file in the University of Malawi College of Medicine library in Blantyre and the University of Malawi's Malawiana collection in Zomba, or ele\$ctronically through UMI Dissertations Online.

\section{A Qualitative Study of Medical Student Socialization in Malawi's College of Medicine: Clinical Crisis and Beyond}

\author{
Claire Wendland ${ }^{1} \&$ Chiwoza Bandawe ${ }^{2}$ \\ 1. Universiry of Wisconsin \\ 2. College of Medicine, Blantyre
}

\section{Introduction}

In a previous report we addressed the socialization of Malawian medical students during the years of basic science training. Here we turn to the heavily clinical training of the final three years of medical school.

\section{Research methods}

Readers wishing a full discussion of the research methods are referred to our previous article. In brief, this was a threephase cross-sectional qualitative research project involving focus groups, semi-structured interviews and questionnaires given to students and recent graduates of the University of Malawi, College of Medicine. The results we present are based on material from 4 focus groups, 31 student and 7 intern interviews (focus groups and interviews included $31 \%$ of all medical students during the 2002-2003 study period), and 121 questionnaires (representing 84\% of all medical students). Material was coded for thematic content using QSR*N6 qualitative research software.

This report presents primarily interview data, and we present as major themes any that arose in at least twenty-five percent of interviews. Where useful, we supplement the analysis with questionnaire and focus group data. ${ }^{a}$ Where statistical analysis was suitable, interview themes were assessed using two-tailed proportion testing. Likert-scale items from questionnaires were analyzed using STATA 7, and effects of binomial categories, linear variables, and ordinal nonlinear variables on Likert scores were measured using t-tests, linear regression, and ordered logit regression, respectively.

\section{Findings}

\section{Experience of Clinical Training}

Our previous report showed that the socialization process of preclinical training for Malawian students, though possessed of some distinctive features, remains fairly close to that described for medical students in the heavily studied North American population. Medical socialization begins to diverge more significantly from the North American or European model when Malawi's students enter the hospital in their third year.

The primary site of clinical instruction is an urban public hospital in Blantyre. Students also spend time in several other public hospital and clinic settings. All these clinical education sites share problems of understaffing, overcrowding, frequently poor staff morale, and intermittent to chronic shortages of medications, diagnostic tests and supplies.

Interview and focus group data reveal that the transition to the clinical setting results in a psychological crisis for many students and increased stress for most. Two of the four focus groups, in addition to several individual interviewees, described increases in student alcohol use among in the third year, though they were not asked about this. Expressions of religious faith and of positive feelings about medicine drop in the third year. Nearly half of clinical students and two thirds of interns voiced strong criticism of the national government, characterizing it especially as unresponsive to the needs of poor Malawians, during this time.

A striking measure of trainee's increasingly troubled relationship with their profession is demonstrated in Table 1 , where responses to a hypothetical question on whether a sibling should become a physician are given. Pre-clinical students were enthusiastic about the idea, nearly all responding either with an unqualified yes or a yes as long as the sibling had good reasons (usually this meant the sibling should not choose medicine as a way to amass wealth). 